\title{
Author Correction: Dairy Manure Wastewater Remediation Using Non-airtight Digestion Pretreatment Followed by Microalgae Cultivation
}

\author{
Liang Wang $^{1} \cdot$ Lide Chen $^{1} \cdot$ Sarah $\mathrm{Wu}^{2} \cdot$ Muhammad Aamir Bashir $^{2}$ \\ Published online: 7 August 2020 \\ C) Springer Science+Business Media, LLC, part of Springer Nature 2020
}

\section{Author Correction: Applied Biochemistry and Biotechnology. https://doi.org/10.1007/s12010-020-03363-1}

The original version of this article unfortunately contained a mistake. The name of the $3 \mathrm{rd}$ author was incorrectly captured as Wu Sarah instead of Sarah Wu. The correct author name is presented here.

Publisher's Note Springer Nature remains neutral with regard to jurisdictional claims in published maps and institutional affiliations.

The online version of the original article can be found at https://doi.org/10.1007/s12010-020-03363-1

\section{Lide Chen}

lchen@uidaho.edu

1 Department of Soil and Water Systems, Twin Falls Research \& Extension Center, University of Idaho, 315 Falls Ave, Twin Falls, ID 83301, USA

2 Department of Biological Engineering, University of Idaho, 875 Perimeter Drive, Moscow, ID 83844, USA 